\title{
Free Field Surface Motion at Different Site Types due to Near-Fault Ground Motions
}

\author{
Jagabandhu Dixit, D. M. Dewaikar, and R. S. Jangid \\ Department of Civil Engineering, Indian Institute of Technology Bombay, Mumbai 400076, PIN, India \\ Correspondence should be addressed to Jagabandhu Dixit, jagabandhu@iitb.ac.in \\ Received 15 May 2012; Accepted 21 June 2012 \\ Academic Editors: A. Streltsov and P. Tosi
}

Copyright ( $) 2012$ Jagabandhu Dixit et al. This is an open access article distributed under the Creative Commons Attribution License, which permits unrestricted use, distribution, and reproduction in any medium, provided the original work is properly cited.

\begin{abstract}
Seismic hazards during many disastrous earthquakes are observed to be aggravating at the sites with the soft soil deposits due to amplification of ground motion. The characteristics of strong ground motion, the site category, depth of the soil column, type of rock strata, and the dynamic soil properties at a particular site significantly influence the free field motion during an earthquake. In this paper, free field surface motion is evaluated via seismic site response analysis that involves the propagation of earthquake ground motions from the bedrock through the overlying soil layers to the ground surface. These analyses are carried out for multiple near-fault seismic ground motions at 142 locations in Mumbai city categorized into different site classes. The free field surface motion is quantified in terms of amplification ratio, spectral relative velocity, and spectral acceleration. Seismic site coefficients at different time periods are also evaluated for each site category due to near-fault ground motions from the acceleration response spectra of free field surface motion at each site and the corresponding acceleration response spectra at a reference rock outcrop site.
\end{abstract}

\section{Introduction}

Seismic response of a structure is dependent upon the nature of supporting soil. Severe structural damages to houses and manmade structures during many past earthquakes are observed to be concentrated in an area where the ground consisted of local alluvial deposits. Local soil deposits are found to have paramount influence on the characteristics of earthquake ground shaking and have played a major role in the damage and loss of life during many disastrous earthquakes such as the 1976 Tangshang, 1985 Mexico, 1989 Loma Prieta, 1994 Northridge, 1995 Kobe earthquakes, 2001 Bhuj earthquake, and 2005 Kashmir earthquake. The profound importance of the nature of the subsoil on the structural response of different types of structures has also been confirmed through several theoretical and experimental studies. The motion at the base of a structure founded on rock is identical to that occurring at the same point before the structure is built, but they are quite different if the structure is founded on soil. The motion that occurs in the soil or rock layers at some depth from the ground surface in the absence of any structure or excavation is defined as freefield motion. The motion at the base of a structure and the free field motion that would occur at the same point in the absence of the structure are different.

The study of wave propagation in horizontal layered media is an integral part of dynamic soil-structure interaction (SSI) analysis and it is the first stage of seismic SSI analysis [1]. Local soil stratigraphy, material heterogeneity, predominant excitation period, and the number of significant cycles have important roles on the characteristics of free field motion. Free field motions can be evaluated by treating the visco elastic soil column as a structure overlying an elastic rock half space with known excitations at the bedrock level. One-dimensional wave propagation theory is employed to simulate the propagation of seismic wave through given soil profiles at 142 sites in Mumbai city using the Standard Penetration Test (SPT) data and 100 selected near-fault acceleration time histories corresponding to several earthquake magnitudes of different fault types. The input seismic ground motion is applied at an assumed rock outcrop below the soil column. The control motion 
can be defined either at the free surface of the site, or at an assumed rock outcrop that is on the level of the rock under the assumption that there is no soil on top or at a point in middle soil layer.

Equivalent shear wave velocity of the soil layers overlying the bedrock is considered to be a fundamental parameter that represents the in situ properties of soil layers. Shear wave velocities of soil profiles can be calculated using the correlation developed in terms of penetration tests if the measured shear wave velocities are unavailable. The contrast in shear wave velocities and damping prevailing at the interface of two layers plays an important role on the amplification of ground motion. The influence of the soft ground at a site on the seismic response of structures is sometimes higher due to a resonance effect when the predominant periods of the structures and site periods are close to each other. The site period and duration of an earthquake increases usually with the softness of the ground. The amplification at sites with soft soil deposits is larger and longer than that compared with the shaking experienced at a hard rock site [2]. The effects of soft soil conditions are generally expressed in terms of fundamental vibration periods of the soil and the bedrock, aggravation factor, spectral acceleration, peak ground acceleration at the bedrock level, and ground surfaces.

\section{Effects of Local Soil Deposits}

The shaking caused by seismic waves can cause damage or collapse of the buildings. Local soil deposits significantly modify the amplitude, duration, and frequency content of free field motion [3]. Nonlinear site response is often demonstrated during the transmission of high intensity seismic waves through the horizontal soil layers. Acceleration records obtained in the near-field region during earthquakes at relatively short distances from the site have demonstrated the significant influence of certain source factors such as fault type, fault orientation, rupture mechanism, and rupture directivity as well as geotechnical site conditions such as properties of soil layers, soil stratification, and depth of ground water table on strong motion characteristics at the ground surface.

The source mechanism and fault rupture are very complex phenomenon. The coupled effect of source, path, and site conditions significantly modifies the characteristics of earthquake ground motion at the ground surface. The source characteristics are very effective and dominant especially in the near-field zones and affect the directional properties of the ground motion [4]. These ground motions with forward-directivity impose high deformation demands and also induce high energy demands to structures. These could have significant energy in low-frequency ranges that can seriously affect long-period structures [5]. Therefore, the effect of near-fault ground motions at the soft soil deposits is imperative to be studied to understand the potential seismic risk. The seismic site response analyses using one- or twodimensional numerical model should consider the variability and uncertainties of the source and site conditions using
TABLE 1: Correlations between $V_{s}$ and SPT $N$ value for all types of soil.

\begin{tabular}{lc}
\hline Imai [6] & $V_{s}=91.0 N^{0.337}$ \\
Ohta and Goto [7] & $V_{s}=85.35 N^{0.348}$ \\
Imai and Tonouchi [8] & $V_{s}=97.0 N^{0.314}$ \\
\hline
\end{tabular}

selected input acceleration time histories to quantify the site effects accurately.

\section{Data Collection}

The characteristics of strong motion near the ground surface are much more affected by site conditions. In an attempt to evaluate the free field motion for an ensemble of near fault earthquakes, SPT soil data with bore log characteristics containing the details of the soil profiles along the depth, namely, number of blow counts in standard penetration test $(N)$, dry density, wet density, specific gravity, and groundwater depth, among others have been collected from 142 representative borehole locations in Mumbai city. The depths of these boreholes are in the range of $7.5 \mathrm{~m}$ to $30 \mathrm{~m}$. The SPT $N$ values are measured at every $1.5 \mathrm{~m}$ depth intervals until rock strata is encountered. Majority of the soil profile data used in this analysis are contributed by DBM Geotechnics and Constructions Pvt. Ltd. and IIT Bombay. The soil profile data used in this study belong to a wide range of soil deposits comprising of sand, silt, clay, clayey sand, silty sand, silty gravel, and so forth, in different layers. The SPT blow counts at some places are in the order of 2 to 10 indicating very soft deposits of clay, whereas at some other places, it is up to 40 showing dense silty sand. The SPT $N$ value at a particular site represents most of the important mechanical properties of the soil required for the site response analysis.

Site conditions play a major role in the amplification of soil sites during seismic events. To evaluate the free field surface motion for different site classes due to near-fault earthquakes, the site conditions have been categorized into different classes according to the mean shear wave velocity of the upper $30 \mathrm{~m}$ below the ground surface $\left(\bar{V}_{\mathrm{s}-30}\right)$ as per the provisions in National Earthquake Hazards Reduction Program [9]. $\bar{V}_{s-30}$ is defined as the ratio of $30 \mathrm{~m}$ to the time for vertically propagating shear waves to travel from $30 \mathrm{~m}$ depth to the surface. Estimation of free field surface motion by one dimensional approach requires shear wave velocity variation with depth as an important input parameter. For this purpose the SPT blow count of soil layers at each borehole is used for the determination of shear wave velocity from the empirical relationship between SPT $N$ value and shear wave velocity $\left(V_{s}\right)$ by Imai [6], Ohta and Goto [7], and Imai and Tonouchi [8] as given in Table 1. These relationships are reported to be valid for a wide range of soil type. The shear wave velocity for the soil layers at each site used in the present study are taken as the average of these three values so obtained. 
Using the shear wave velocities of the soil layers, $\bar{V}_{s-30}$ is calculated as,

$$
\bar{V}_{s-30}=\frac{\sum_{i=1}^{n} d_{i}}{\sum_{i=1}^{n}\left(d_{i} / V_{s i}\right)},
$$

where $d_{i}$ and $V_{s i}$ are the thickness and the shear wave velocity $\left(V_{s}\right)$ of $i$ th soil or rock layer to depth of $30 \mathrm{~m}$, respectively, $\left(\sum d_{i}=30 \mathrm{~m}\right)$ and $n$ is number of layers. This site classification approach suggests that 39 sites of 142 available sites correspond to C-type $\left(360 \mathrm{~m} / \mathrm{s} \leq \bar{V}_{s-30} \leq 760 \mathrm{~m} / \mathrm{s}\right), 94$ sites correspond to D-type $\left(180 \mathrm{~m} / \mathrm{s} \leq \bar{V}_{s-30} \leq 360 \mathrm{~m} / \mathrm{s}\right)$, and 9 sites correspond to E-type $\left(\bar{V}_{s-30}<180 \mathrm{~m} / \mathrm{s}\right)$ (Figure 7$)$.

\section{Seismic Input Excitation}

Multiple near-fault strong ground motions comprising of 100 recorded acceleration time histories with peak ground acceleration (PGA) $0.1 \mathrm{~g}$ to $1.3 \mathrm{~g}$ of earthquakes of magnitudes $M_{w} 5.5$ to $M_{w} 7.8$ are downloaded from the strong motion database of Pacific Earthquake Engineering Research [10] center to excite at the bottom of the soil column consisting of horizontal layers overlying the elastic rock half space. The distance of recording station from the location of fault rupture is less than or equal to $10 \mathrm{~km}$. These long-period pulse-type ground motions correspond to different source mechanisms and fault orientations. The seismic ground motions are nonstationary with respect to both amplitude and frequency. The near-fault acceleration time histories are characterized by long-period high-velocity pulse, higher frequencies, and short-duration strong-impulsive motion with considerable energy in the long-period regions due to short travel distance [11]. Figure 1 shows acceleration, velocity, and displacement time history of a typical nearfault ground motion for 1992 Landers earthquake recorded at Lucerne. The magnitude $\left(M_{w}\right)$, epicentral distance $(R)$, and PGA of near-fault acceleration time histories used in this study are shown in Figure 2.

The PEER [10] ground motion database includes the set of the most important ground motions recorded worldwide and includes corresponding earthquake magnitude, style of faulting, epicentral distance, site type at the recording stations, and so forth. This database is considered to be a reliable source of ground, motion and these ground motions are used for assessing seismic performance of structures and for analyzing the responses at sites due to a suite of strong ground motions. The response at a site is greatly influenced by source characteristics, path characteristics, local site conditions epicentral distance, and other relevant engineering parameters. The main purpose of this paper is to carry out a typical study to observe the responses at sites of different site types categorized based on average shear wave velocity due to near-fault ground motion. Due to the availability of the details of soil profiles at several sites of different categories in Mumbai city, those are chosen for this typical analysis.

The acceleration response spectra have been calculated for each of the acceleration-time histories used in this study. The mean $(\mu)$ and standard deviation $(\sigma)$ of all
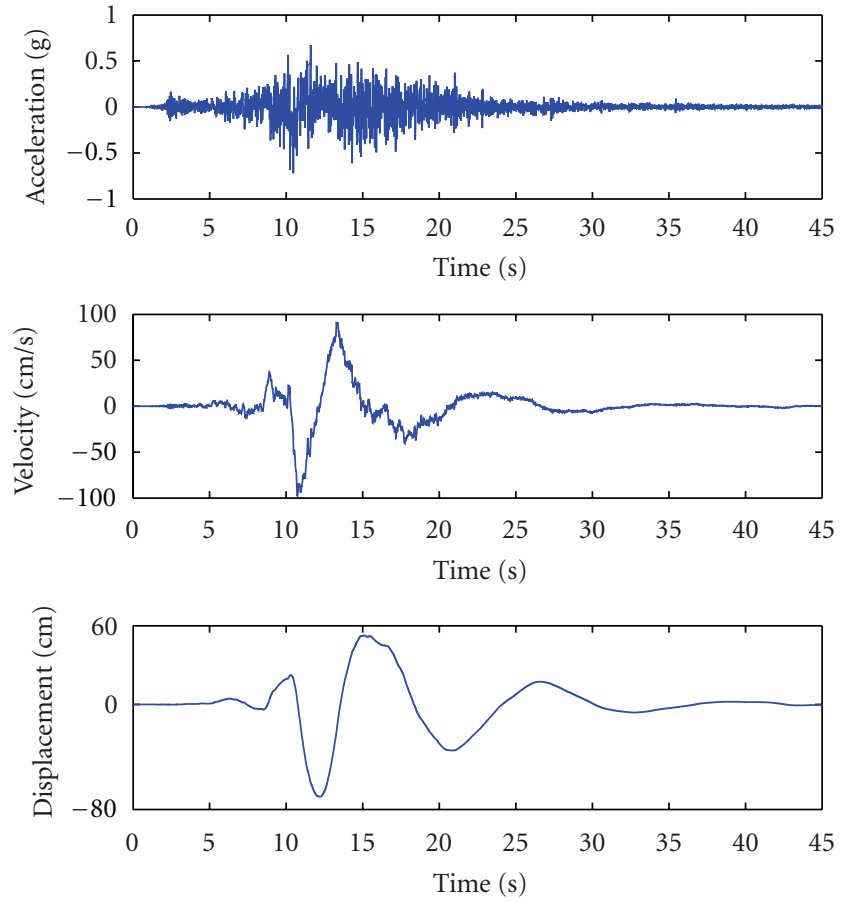

Figure 1: Acceleration-, velocity-, displacement-time histories of 1992 Landers earthquake recorded at Lucerne $\left(M_{w}=7.3, R=\right.$ $1.1 \mathrm{~km})$.

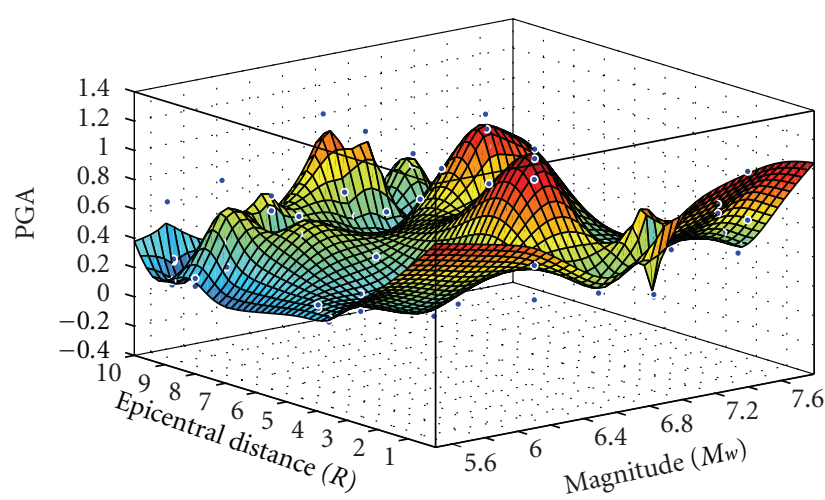

Figure 2: Magnitude $\left(M_{w}\right)$, epicentral distance $(R)$, and PGA of near-fault ground motions selected for the present study.

the acceleration-time histories taken together are shown in Figure 3.

A huge amount of energy is released in a short time period in case of the pulse-type motions with forward directivity. Forward directivity is caused due to propagation of the fault rupture towards the site. The fault-normal ground motions are significantly larger than the fault-parallel motions at higher periods. In this study, both fault-normal and fault-parallel components are considered to address their effects on the free field motion. 


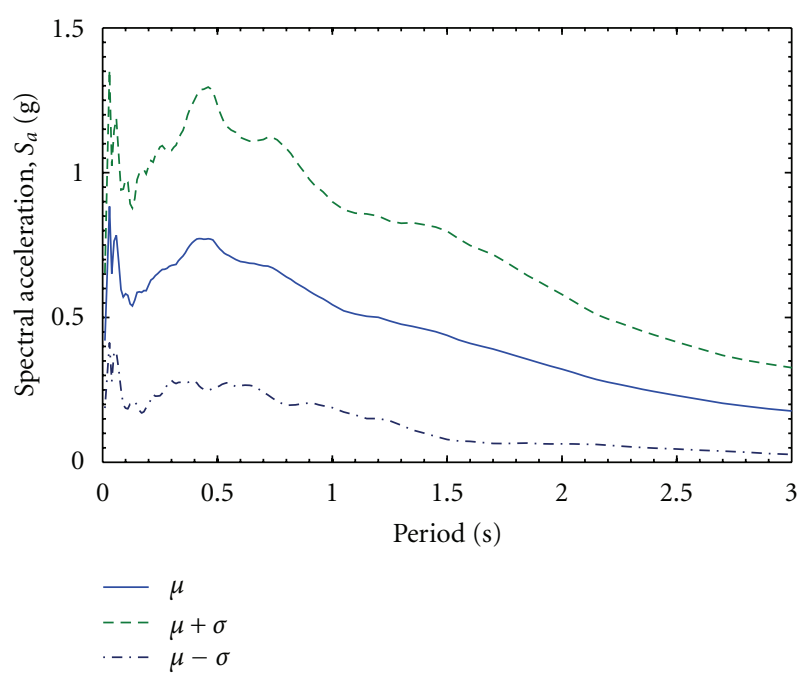

Figure 3: Mean and standard deviation of acceleration response spectra of selected near-fault ground motions.

\section{Evaluation of Free Field Motion}

A comprehensive assessment of free field motion should consider source characteristics as well as geotechnical and geological site conditions. The free field surface motions are the result of wave reflection, refraction, and surface wave propagation. The major factors modifying the free field surface motions are depth of the soil column, the dynamic properties of soil layers, the type of rock strata, and properties of ground motion. The input ground motions are excited at the bottom of the soil column. Each soil layer in the soil column overlying the bedrock is assumed to be horizontal and homogeneous. One-dimensional wave propagation equation for vertically propagating shear waves through the linear viscoelastic system consisting of $n$ layers is expressed as the following damped wave equation in the time domain:

$$
\rho_{j} \frac{\partial^{2} u}{\partial t^{2}}=G_{j} \frac{\partial^{2} u}{\partial z^{2}}+\eta_{j} \frac{\partial^{3} u}{\partial z^{2} \partial t},
$$

where $u$ is the horizontal displacement, $t$ is time, $z$ is the depth within $j$ th layer, $\rho_{j}, G_{j}$, and $\eta_{j}$ are mass density, shear modulus, and viscosity, respectively, of $j$ th layer.

Equivalent linear one-dimensional wave propagation analyses are performed at 142 soil sites in Mumbai city for 100 near-fault strong motion using computer program SHAKE91 [12]. The site responses are computed in the frequency domain using equivalent shear modulus and equivalent damping ratios. Figure 4 shows a typical site response analysis at a site in Mumbai city. It shows the soil profile, shear wave profile, input excitation at the bedrock level, and the free field motion at the ground surface. The acceleration response spectra for both rock level and surface level motions are evaluated. The characteristics of free field motions can be quantified by amplification spectra, relative spectral velocity, acceleration response spectra, site coefficients, and so forth. Amplification spectra are defined in the frequency domain as the ratio of amplitude of free

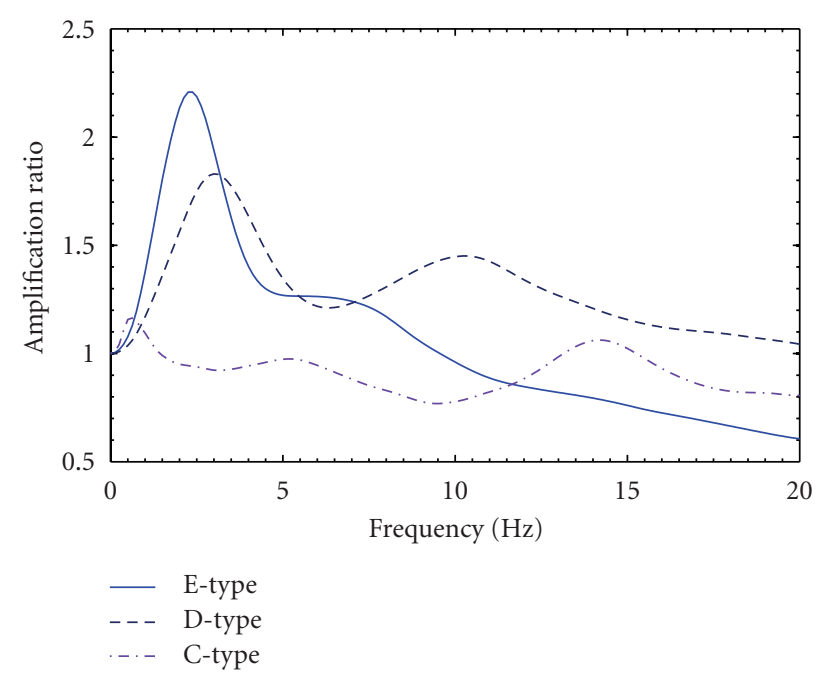

Figure 4: Amplification ratio at 5\% damping at C-, D-, and E-type sites.

field motion at the surface level at different frequencies to the amplitude at the bedrock level at corresponding frequencies [13].

One-dimensional site response analysis is justified for horizontal grounds. The surface level free field motion at any particular site type in this study is obtained by taking the mean of the free field motions at all the sites of same category due to all the near-fault ground motion. Soil nonlinearity has a limited influence on mean free field motion at a site and the equivalent linear approach suitably takes care of the nonlinear aspects. SHAKE91 [12] is most widely used computer programs for site response analysis due to its simplicity and relative accuracy. Results obtained from SHAKE91 [12] compare well with field measurements. The sensitivity of this program to parameter variations is acceptable for most practical applications. Equivalent linear approach used in SHAKE91 [12] is based on viscoelastic constitutive model. The equivalent linear approach is computationally efficient and easy to implement. The shear modulus and damping ratio of the various soil layers at different strain levels are iteratively updated during the analysis through modulus degradation and damping curves to obtain revised values of shear modulus and damping of the materials constituting the different layers and the revised shear modulus and damping ratio are compatible with the deformation level induced in each soil layer by the seismic force. The algorithm of fast Fourier transform implemented in SHAKE91 [12] program allows performing the analysis in the frequency domain in an iterative procedure till a converged solution is arrived. SHAKE91 [12] is considered appropriate if the number of runs is significantly high. The number of runs of the program in the present study is 14200 . However, for the sites involving slopes or earth retaining structures one-dimensional analysis has to be used judiciously. Two-dimensional equivalent linear or nonlinear site response analysis should be performed when one-dimensional analysis is not adequate. 
SHAKE 91 [12] captures nonlinear cyclic response of soil through equivalent linear approximation by modifying the linear elastic properties of the soil based on the induced strain level. An effective shear strain is computed as 65\% of peak strain for each soil layer for a given acceleration time series and an initial estimate of modulus and damping values. The strains induced in soil layers depend on the soil properties. Shear modulus and damping ratios vary with Fourier amplitude of shear strain. The strain compatible shear modulus and damping ratio values are iteratively calculated.

Similarly, site coefficients are the ratio of spectral acceleration of free field surface motion at a site at different periods to that of the assumed reference outcrop rock site at those corresponding periods [14]. Site coefficients can be expressed as

$$
F_{s}(T)=\frac{S_{a}^{s}(T)}{S_{a}^{r}(T)},
$$

where $S_{a}^{s}(T)$ and $S_{a}^{r}(T)$ are the acceleration response spectra at different periods at the surface level and reference outcrop rock site respectively. $F_{s}(T)$ are site coefficients at corresponding periods.

\section{Results}

Amplification spectra are evaluated individually at each site for 100 input excitations at 5\% damping, followed by the evaluation of mean amplification spectrum at each site. Amplification spectrum for C-, D-, and E-type sites for nearfault ground motions are evaluated from mean amplification spectrum at different sites as depicted in Figure 4. The amplification is found to be more at low frequency for soft soil sites and deamplification occurs at higher frequencies. Soil profiles at D- and E-type sites being softer than that at Ctype sites show appreciable amplification up to a factor of 2.5 at certain frequency. The majority of C-type sites considered in this study consist of alternate layers of dense sand and clay underlain by thick layers of soft rock.

The spectral relative velocity and spectral acceleration response of ground motion at a reference rock outcrop and the corresponding spectral acceleration response at the surface level for $5 \%$ damping are estimated considering all of these near-fault input motions. Mean spectral relative velocity for different site categories is evaluated from velocity response at each site as shown in Figure 5. The mean acceleration response spectra of free field surface motion and its corresponding standard deviation are evaluated for C-, D, and E-type sites as shown in Figure 6 through Figure 8. A significant difference in frequency, duration, and amplitude of the free field surface motions are observed for different site categories. Site coefficients for C-, D-, and E-type sites are shown in Figure 9. These coefficients are highly dependent upon the site category. There is no significant variation in the values of site coefficients with respect to periods in case of dense soil or soft rock sites. A shift in peak response towards higher periods is also observed in the surface level time history. These site coefficients are smaller at higher values of spectral acceleration values at the reference rock site.

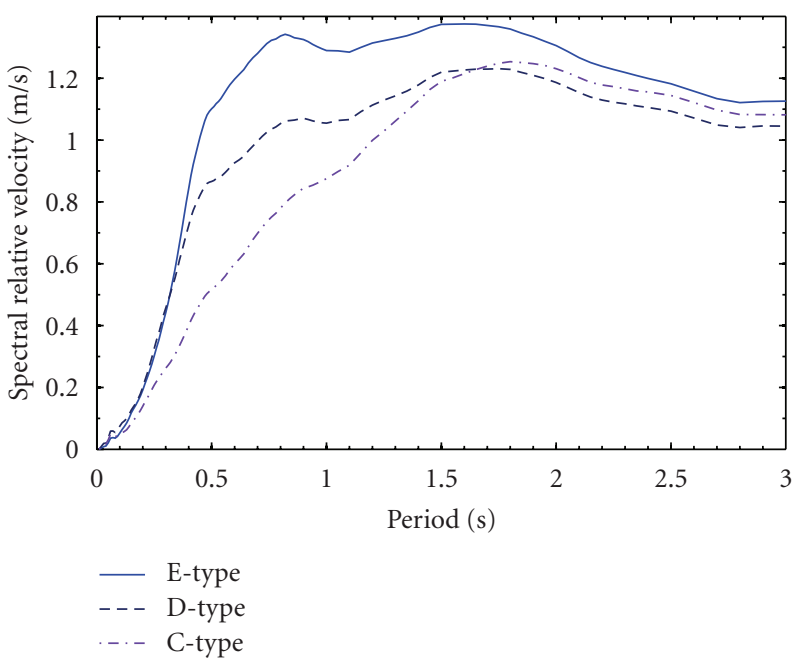

FIGURE 5: Spectral relative velocity at 5\% damping of at C-, D-, and E-type sites.

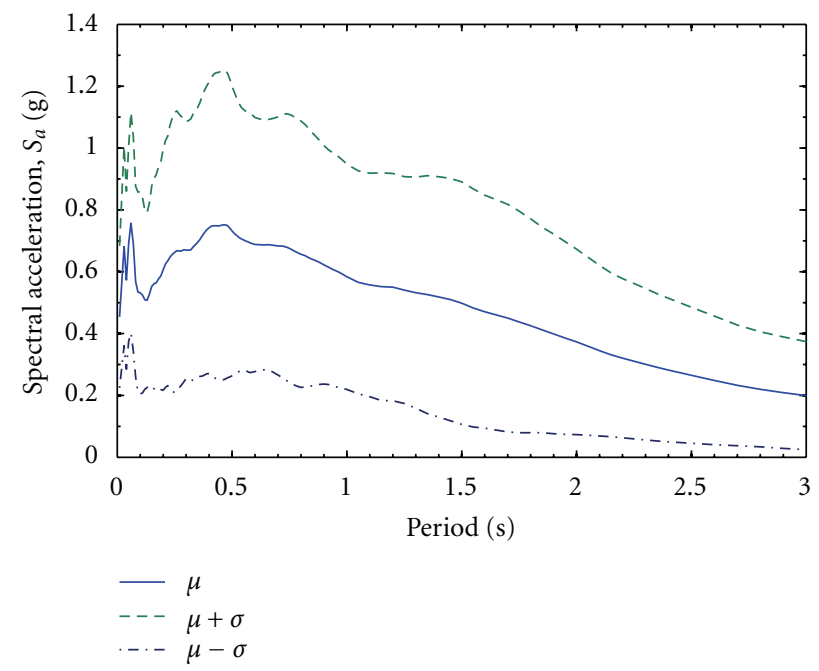

FIGURE 6: Spectral acceleration at C-type sites for near-fault motion.

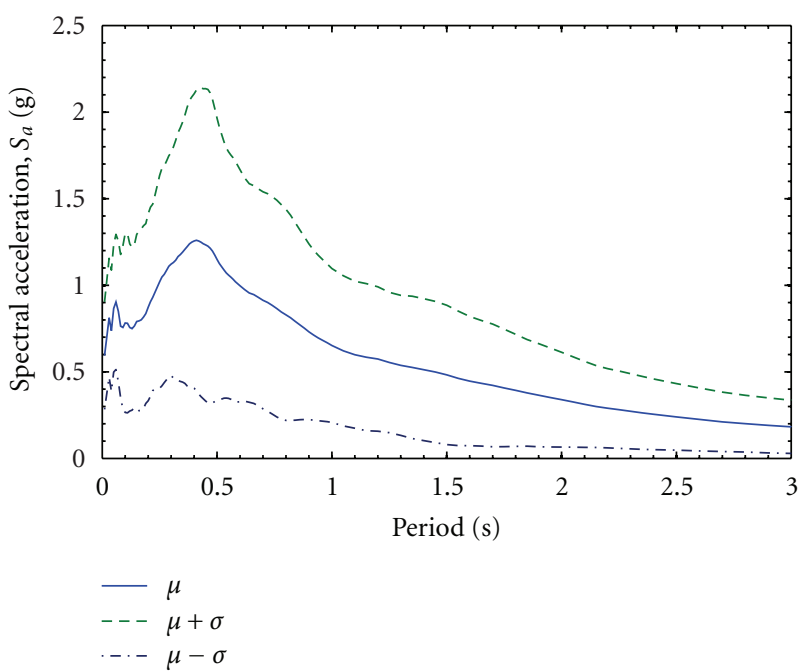

Figure 7: Spectral acceleration at D-type sites for near-fault motion. 


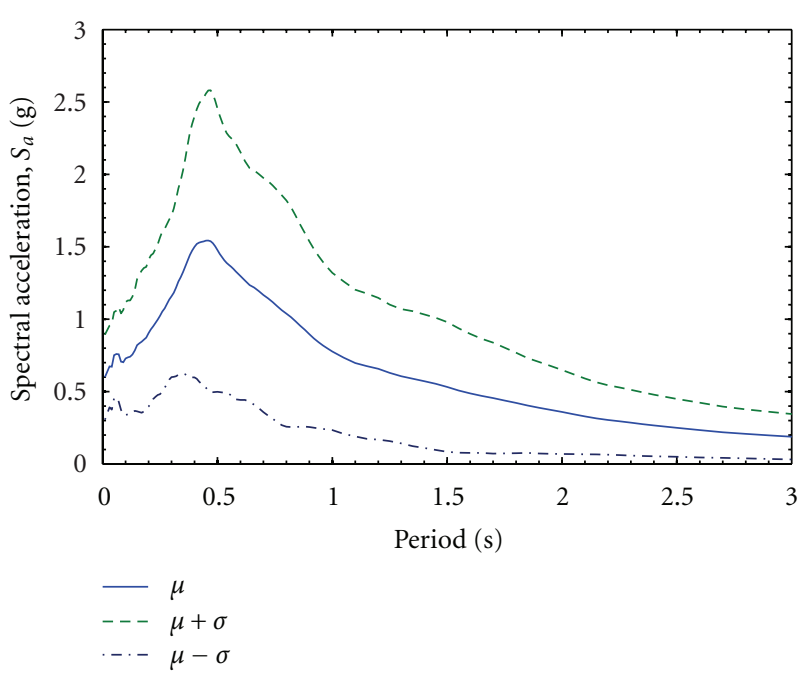

FIGURE 8: Spectral acceleration at E-type sites for near-fault motion.

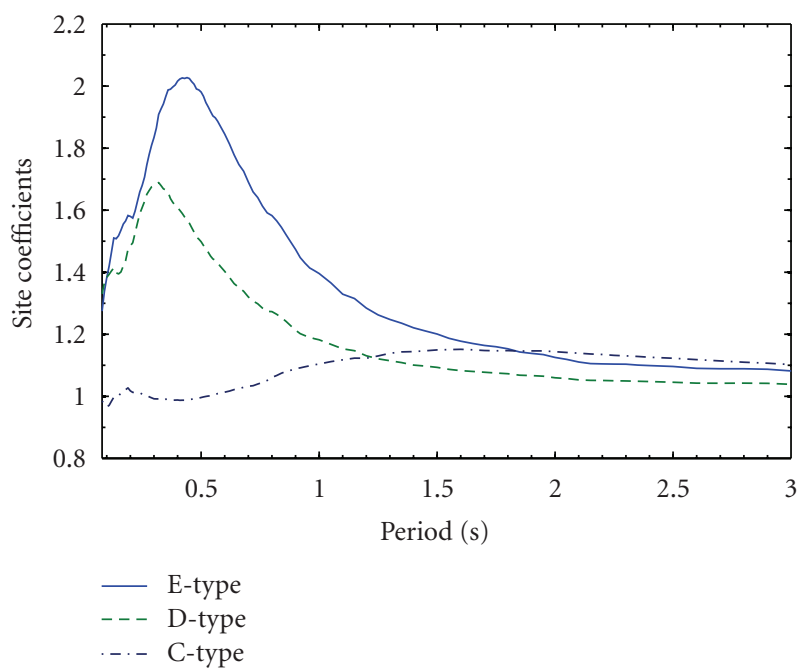

FIGURE 9: Site coefficients for near-fault ground motion.

\section{Conclusions}

Free field surface motion is evaluated for 100 near-fault strong ground motions of different magnitudes. Dynamic properties of soil column and ground motion characteristics are found to have a significant influence on free field surface motion. Free field surface motions are quantified in terms of amplification ratios, acceleration response spectra, and site coefficients. The free field surface motions and the corresponding response spectra are found to be significantly affected by the geological and geotechnical characteristics of local soil deposits. The effect of soil nonlinearity is also shown at higher peak ground accelerations.

\section{Acknowledgments}

The authors extend their acknowledgments to M/S DBM Geotechnics and Constructions Pvt. Ltd., Mumbai, for providing the borehole data at different sites at Mumbai city.

\section{References}

[1] J. Wolf, Dynamic Soil-Structure Interaction, Prentice Hall, Englewood Cliffs, NJ, USA, 1985.

[2] R. D. Borcherdt, "Estimates of site-dependent response spectra for design (methodology and justification)," Earthquake Spectra, vol. 10, pp. 617-653, 1994.

[3] K. Aki, "Local site effects on weak and strong ground motion," Tectonophysics, vol. 218, no. 1-3, pp. 93-111, 1993.

[4] G. P. Mavroeidis and A. S. Papageorgiou, "A mathematical representation of near-fault ground motions," Bulletin of the Seismological Society of America, vol. 93, no. 3, pp. 1099-1131, 2003.

[5] J. F. Hall, T. H. Heaton, M. W. Halling, and D. J. Wald, "Nearsource ground motion and its effects on flexible buildings," Earthquake Spectra, vol. 11, no. 4, pp. 569-605, 1995.

[6] T. Imai, "P- and S-wave velocities of the ground in Japan," in Proceedings of the 9th International Conference on Soil Mechanics and Foundation Engineering, pp. 257-260, Tokyo, Japan, 1977.

[7] Y. Ohta and N. Goto, "Empirical shear wave velocity equation in terms of characteristic soil indexes," Earthquake Engineering and Structural Dynamics, vol. 6, no. 2, pp. 167-187, 1978.

[8] T. Imai and K. Tonouchi, "Correlation of N-value with Swave velocity and shear modulus," in Proceedings of the 2nd European Symposium of Penetration Testing, pp. 57-72, A. A. Balkema Publishers, Amsterdam, The Netherlands, 1982.

[9] BSSC, NEHRP Recommended Seismic Provisions for New Buildings and other Structures, Building Seismic Safety Council, Federal Emergency Management Agency, Washington, DC, USA, 2009.

[10] PEER, Pacific Earthquake Engineering Research Center, "PEER Strong Motion Database," http://peer.berkeley.edu/ smcat/.

[11] P. G. Somerville, "Engineering characteristics of near fault ground motion," in Proceedings of the Seminar on Utilization of Strong Motion Data (SMIP '97), Los Angeles, Calif, USA, 1997.

[12] I. M. Idriss and J. I. Sun, "A Computer program for conducting equivalent linear seismic response analysis of horizontally layered soil deposits," in Users Manual For SHAKE91, Center for Geotechnical Modeling, Department of Civil and Environmental Engineering, University of California, Davis, Davis, Calif, USA, 1992.

[13] S. L. Kramer, Geotechnical Earthquake Engineering, Prentice Hall, Upper Saddle River, NJ, USA, 1996.

[14] H. H. M. Hwang, H. Lin, and J. R. Huo, "Site coefficients for design of buildings in eastern United States," Soil Dynamics and Earthquake Engineering, vol. 16, no. 1, pp. 29-40, 1997. 

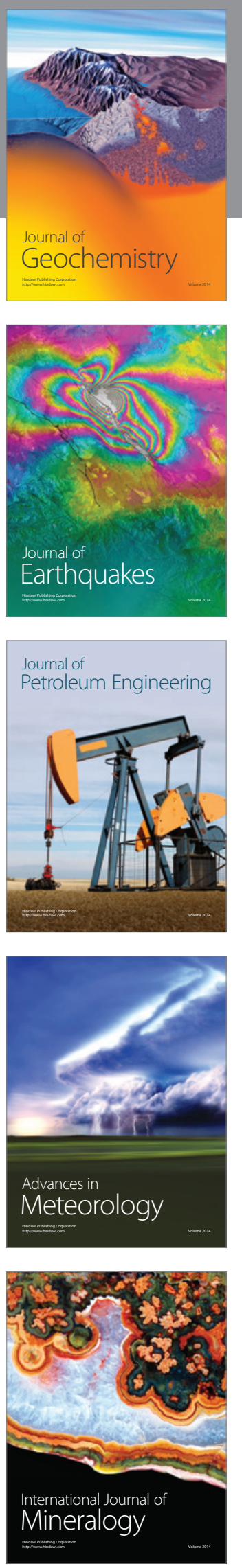
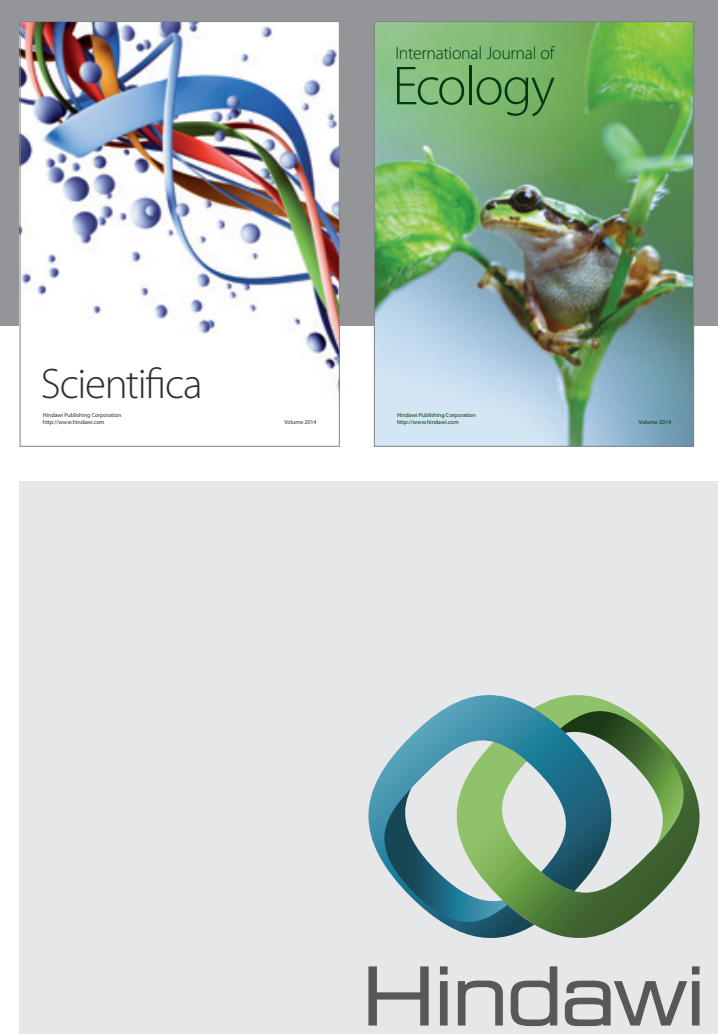

Submit your manuscripts at http://www.hindawi.com
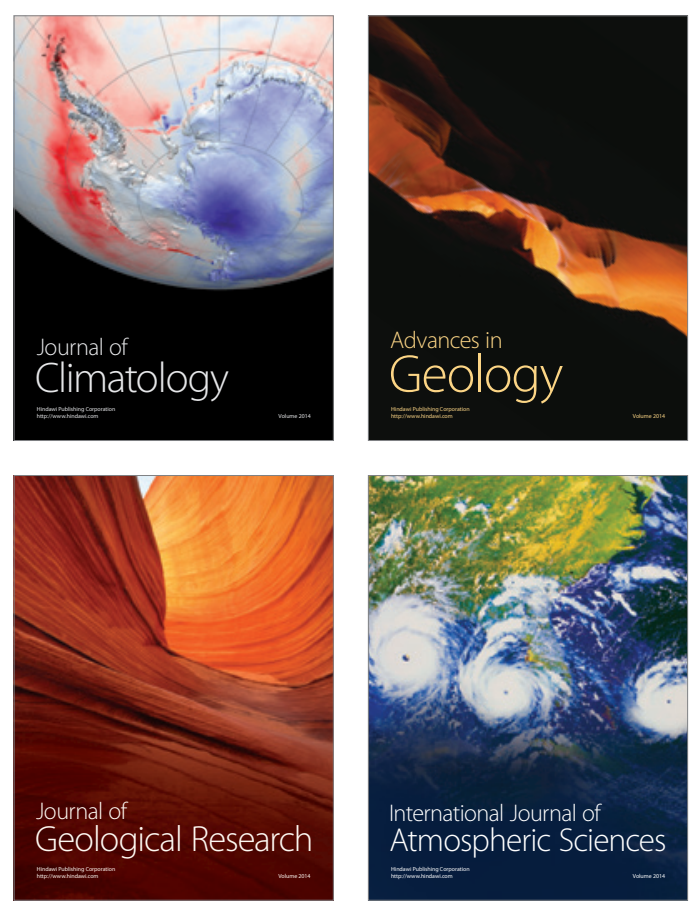
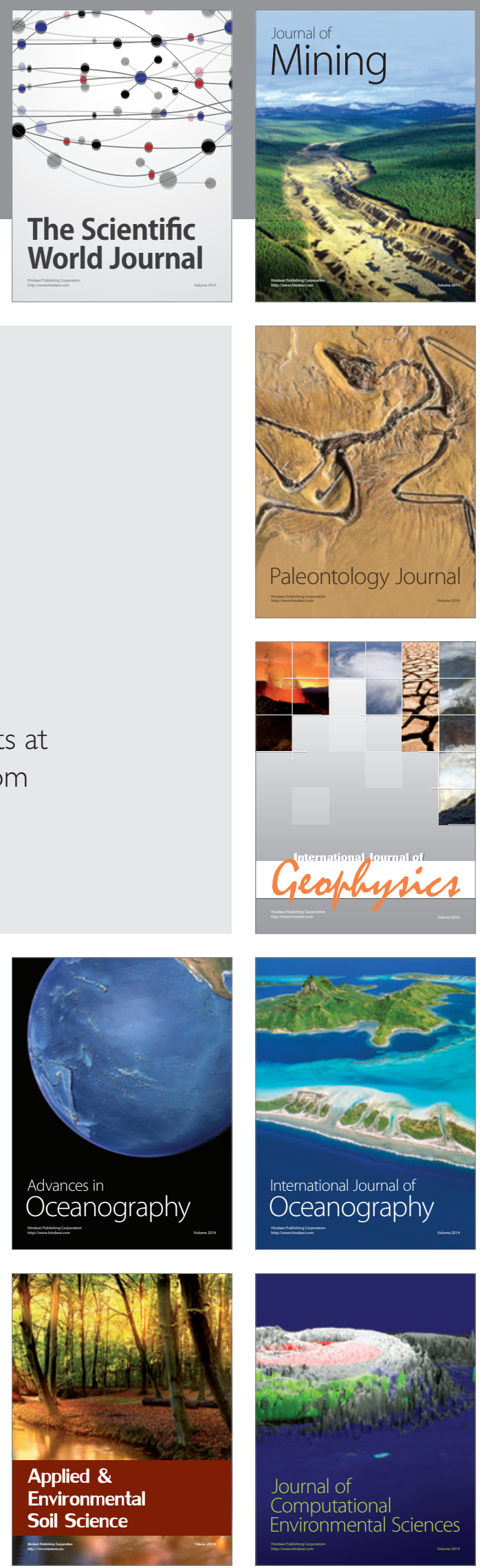